\title{
Problem of the Care of Digestive Surgical Emergencies at the Visceral Surgery Department of Donka National Hospital in Conakry
}

\author{
Baldé Abdoulaye Korsé ${ }^{1}$, Camara Fodé Lansana ${ }^{1}$, Diakité Saikou Yaya ${ }^{1}$, Baldé Habiboulaye ${ }^{1}$, \\ Camara Soriba Naby ${ }^{2}$, Camara Alpha Kabiné ${ }^{3}$, Baldé Oumar Taibata ${ }^{1}$, Diallo Amadou Dioulde ${ }^{1}$, \\ Barry Alpha Madiou ', Sylla Hamidou ${ }^{1}$, Doumbouya Bourlaye ${ }^{1}$, Touré Ibrahima ${ }^{1}$, Diakite Sandaly ${ }^{4}$, \\ Baldé Thierno Mamadou ${ }^{1}$, Soumaoro Labilé Togba ${ }^{4}$, Fofana Houssein ${ }^{4}$, Touré Aboubacar ${ }^{4}$, \\ Diallo Aissatou Taran ${ }^{4}$, Diallo Biro ${ }^{1}$

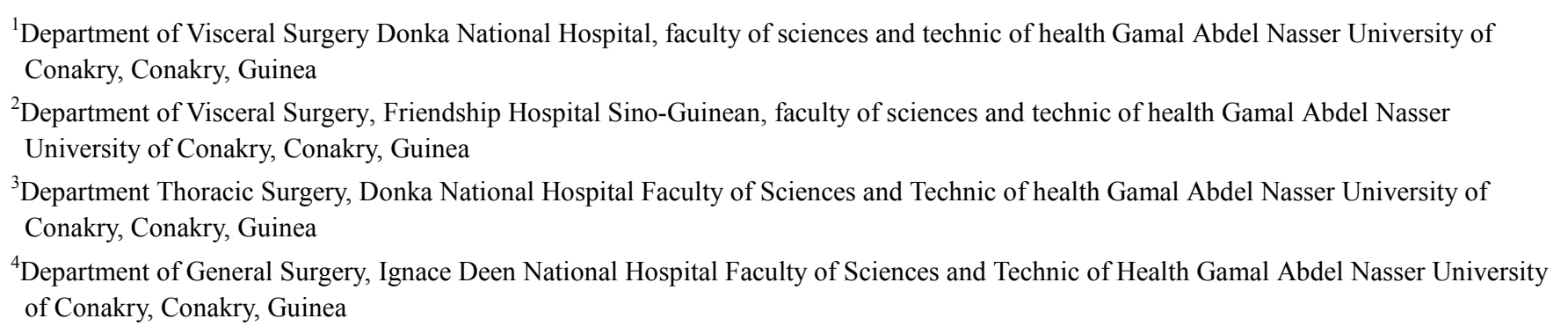

Email address:

cnabysoriba@yahoo.com (C. S. Naby)

${ }^{*}$ Corresponding author

To cite this article:

Baldé Abdoulaye Korsé, Camara Fodé Lansana, Baldé Habiboulaye, Diakité Saikou Yaya, Camara Soriba Naby, Camara Alpha Kabiné, Baldé Oumar Taibata, Diallo Amadou Dioulde, Barry Alpha Madiou, Sylla Hamidou, Doumbouya Bourlaye, Touré Ibrahima, Baldé Thierno Mamadou, Soumaoro Labilé Togba, Fofana Houssein, Touré Aboubacar, Diallo Aissatou Taran, Diallo Biro. Problem of the Care of Digestive Surgical Emergencies at the Visceral Surgery Department of Donka National Hospital in Conakry. Advances in Surgical Sciences. Vol. 9, No. 1, 2021, pp. 1-5. doi: 10.11648/j.ass.20210901.11

Received: December 29, 2020; Accepted: December 21, 2020; Published: February 9, 2021

\begin{abstract}
Introduction: The goal was to highlight the issue of management of digestive surgical emergencies in our department. Methods: This was a prospective study that brought together patients treated for digestive surgical emergencies over a 10-month period (January - October 2014). Results: We collected 135 patients or 21\% of all abdominal surgical conditions during the period $(\mathrm{N}=649)$. The average age of our patients was 34 years (range: 11 and 80 ); The sex ratio was 2.19 . Public transport was the means used by patients. The reasons for consultation were: abdominal pain $(89.63 \%)$, vomiting $(77.78 \%)$, cessation of materials and gas (60\%). The average consultation time was 6 days (range: 2 hours and 21 days). Acute generalized peritonitis was the most common (44.44\%). The average time to treatment was 11 hours (range: 1 and 29 hours). The management was medico-surgical. The postoperative consequences were simple in $(50.37 \%)$, the postoperative complications were dominated by parietal infection (30.53\%), evisceration $(3.70 \%)$ and scrotal hematoma $(2.96 \%)$. One death was noted in (17.04\%). The average length of stay was 12 days (range: 1 and 54 days). Conclusion: The management of digestive surgical emergencies remains a challenge. Morbidity and mortality would be revised downwards by reducing the diagnostic delay due to dysfunction of the care system and problems of access to care.
\end{abstract}

Keywords: Emergency, Digestive Surgery, Management 


\section{Introduction}

Surgical emergencies require immediate management, as these are conditions that cause patients to succumb within minutes or hours [1]. They come under several etiologies, grouping together: infectious emergencies (appendicitis, peritonitis); occlusive (occlusion of the small bowel on a bridle, strangulated hernia) and traumatic (ruptured spleen, weapon wound) $[2,3]$. Surgical digestive emergencies still pose a problem of care, especially in hospitals in the Third World [2]. The aim of this study was to highlight the difficulties encountered in terms of diagnostic and therapeutic management of digestive surgical emergencies in our department in order to improve the prognosis.

\section{Methodology}

This was a prospective descriptive study of ten (10) months from January 1 to October 31, 2014. All patients treated for digestive surgery emergencies during the study period were included in our study. Patients admitted for nondigestive emergency surgery and for unoperated digestive emergency were excluded from this study.

Our study variables were epidemiological, clinical, therapeutic and prognostic.

\section{Results}

We collected 135 patients or $21 \%$ of all abdominal surgical conditions during the period $(\mathrm{N}=649)$. The average age of our patients was 34 years with extremes of 11 and 80 years; We noted a male predominance in 93 cases against 42 female; the sex ratio was 2.19. Due to a lack of medical transport, all of our patients arrived in our department by public transport. The clinical signs that prompted the consultation were dominated by abdominal pain $89.63 \%(\mathrm{n}=121)$, vomiting $77.78 \%(\mathrm{n}=105)$ and stopping of materials and gas $60 \%$ $(\mathrm{n}=81)$. The examination objectified a generalized or localized peritoneal reaction in 74 cases $(54.81 \%)$, abdominal contracture in 59 cases $(43.70 \%)$, abdominal distension in 19 cases $(14.07 \%)$ and shock in 17 cases $(12.59 \%)$. Paraclinically, the biological assessment was possible in $59.26 \%$ of cases $(\mathrm{n}=80)$ among which 27 or $20 \%$ presented one or more signs of major poly-visceral disturbance: anemia, hyperleukocytosis, hyper-creatinemia, hyperglycemia. Medical imaging was a contributing factor whenever it was performed. In 78 cases $(57.77 \%)$, the unprepared abdominal X-ray showed either pneumoperitoneum $(29.62 \% ; \mathrm{n}=40)$ or hydro-aeric levels $(28.14 \% ; n=38)$. While the ultrasound revealed a blood effusion in the peritoneal cavity in 4 cases $(2.96 \%)$ where it was performed. The average consultation time was 6 days with extremes of 2 hours and 21 days. Acute generalized peritonitis was represented in 62 cases $(45.92 \%)$ of which 2 $(1.48 \%)$ were consecutive to post-traumatic colo-hail perforation and $18(13.33 \%)$ of appendicular origin. In addition, there were $40(29.62 \%)$ ulcer perforations, including 5 (3.70\%) gastric; 35 (25.92\%) duodenal and 2 $(1.48 \%)$ typhoid perforations. In second place were acute intestinal obstructions in 49 cases $(36.29 \%)$ including 23 (17.03\%) hernial strangulation, $13(9.62 \%)$ obstructions by volvulus, including 8 by pelvic colon volvulus and 5 by volvulus hail; $12(8.88 \%)$ occlusions on hailic colo flanges and $1(0.74 \%)$ colic by obstructive tumor. Acute appendicitis was noted in 14 cases $(10.37 \%)$ and post-traumatic splenic rupture in 10 cases $(7.4 \%)$.

The average consultation time was 6 days with extremes of 2 hours and 21 days. The average pick-up time was 11 hours with extremes of 1 and 29 hours. The management was medico-surgical. The surgical procedures depended on the aetiologies. These were dominated by perforation of duodenal ulcer, gastric ulcer and ileo-colic $32.59 \%(n=44)$. In 43 of these patients, an avive suture was performed with or without an omental patch, while the ileal perforation required end-to-end anastomosis resection with toilet and drainage in all patients. The forty-nine $(36.29 \%)$ acute intestinal obstruction benefited from obstacle removal by section of flanges in 13 cases $(9.62 \%)$, detorsion of colo-hail volvulus in 13 cases $(9.62 \%)$ including 5 resection-anastomoses of the small intestine; 3 endoscopic detorsions, 4 resection-ostomies including 3 according to Bouilli Volkman and 1 Hartman, 1 colonic anastomosis resection. While herniorrhaphy was performed in 23 cases (17.03) of secondary occlusion with hernial constriction of which one case $(0.74 \%)$ required ileal resection with end-to-end anastomosis. Thirty-two $(23.70 \%)$ appendectomies were performed: 18 cases $(13.33 \%)$ of PAG of appendicular origin with toilet and drainage of the abdominal cavity and 14 cases $(10.37 \%)$ for acute appendicitis.

The postoperative consequences were simple in $50.37 \%$ $(n=68)$, postoperative complications were dominated by parietal infection in $25.93 \%(\mathrm{n}=35)$, evisceration $3.70 \%$ $(n=5)$ and scrotal hematoma $2.96 \%(n=4)$. One death was noted in $17.04 \%(n=23)$. The causes of death were poly visceral failure by septic shock in 15 cases $(65.22 \%)$ of PAG, hypovolemic shock in 7 cases (30.43\%) of OIA and hemorrhagic shock in 1 case (4.35) trauma to the abdomen. The average length of stay was 12 days with extremes of 1 and 54 days.

Of the 80 patients $(59.25 \%)$ seen again after a follow-up of 2 years, 6 were reviewed for a late complication, including 4 postoperative eventrations $(5.0 \%)$ and 2 OIA by flanges $(2.5 \%)$.

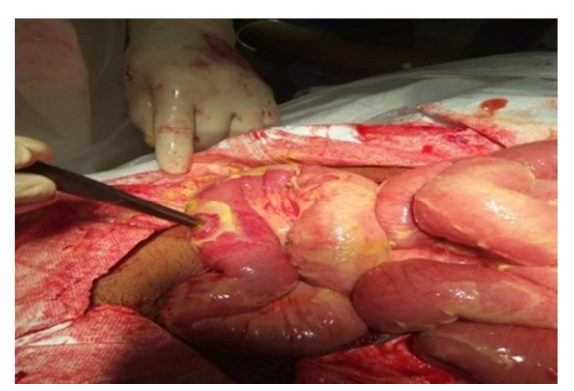

Figure 1. Ileal peritonitis of traumatic origin. 




Figure 2. Ileosigmoid node.

\section{Discussion}

The frequency of digestive surgical emergencies varies from author to author within the same country and from country to country. Thus, in Niger abdominal surgical emergencies by Harouna $\mathrm{Y}$ et al [2], emergencies in digestive surgery constitute an important part of the activities of the emergency department. It concerned 742 patients, ie $3.7 \%$ of the activities of the emergency department; $25.6 \%$ of surgical emergencies and $62 \%$ of surgical procedures. Lebeau R et al. [4] in 2011 reported 137 non-traumatic digestive surgical emergencies in 4208 patients operated on urgently, ie 3.25\% of cases. Although frequent, our results are lower than those of others, because during our study period, the Ebola virus epidemic had a great influence on hospital attendance.

In countries with a high standard of living, emergency gastrointestinal surgery is increasingly common in elderly patients. In Africa, it constitutes a real public health problem because it mainly affects a young active population [5]. In Harouna Y's series [2], digestive surgical emergencies were the preserve of all ages with a predilection in young adults. The same findings have been reported by Cassina P. [6] in Germany and Solagberu [7] in Nigeria who observed that digestive surgery emergencies concerned young adults with an average age ranging from 30 to 40 years. Chaibou MS et al. In the series 8] in 2010 reported the same observations at L'Hôpital National de Niamey with a mean age of 27.32 years and extremes of 3 months and 72 years.

In our study as reported by most African authors, digestive surgical emergencies concerned the young adult. This could be explained by the elective frequency of certain conditions in this population. In African, Asian and European literature $[3,12,13]$, digestive surgical emergencies concern young adult males. Keita $\mathrm{M}$ et al. [6] in their study carried out at the CHU Point $\mathrm{G}$ in Bamako found a male predominance with a sex ratio equal to 1.5 in favor of men. Harissou A et al [8] reported in their series a male predominance with a sex ratio of $3 / 1$.

In our study, digestive surgical emergencies were observed a lot in men, daily stress and road accidents would explain this male predominance.

Poor road infrastructure and insufficient means of medical transport constitute an obstacle to accessibility to health centers in developing countries [8]. In the series by Keita M et al. [6], $23.4 \%$ of their patients benefited from medical transport. In our series, as in that of $\mathrm{N}$ rasamoelina et al [14], no patient benefited from this type of transport. The poor road infrastructure, the insufficiency and the high cost of prehospital medical services in the country would explain the high frequency of non-medical transport in our study and undoubtedly contribute to the worsening of the patient's condition which is led to the hospital without precaution.

Several African authors Gutpa S. K; Rasamoelina N; Harouna $Y$ et al $[15,14,3]$, reported that the admission delay is usually long in the tropics, attributable to certain traditional medicine practices (use of decoction, self-medication), to the low economic power of patients who have at their expense the costs of consultation, hospitalization and treatment as well as diagnostic errors during the initial consultation often carried out in private practices by untrained staff.

In the series by Lebeau $\mathrm{R}$ et al. [7] the average time to admission was 5.5 days, with extremes of 6 hours and 30 days. In our study, the time to admission was longer than that of

Lebeau R. The low socioeconomic level of the population, which has to pay all the costs inherent in its care out of pocket, explains this delay in admission.

Delay in treatment was the main prognostic factor reported in all African studies [3, 14]. Very often linked to the insufficiency of qualified personnel, the unavailability of certain resuscitation drugs in the hospital, the unavailability of certain emergency examinations and the financial problems of families for the execution of prescriptions and certain examinations (biology and radiology) [8, 14]. Harouna $\mathrm{Y}$ et al. [3]. Reported in their series an average time to management equal to 3 hours between admission to the emergency department and surgery. In the series by Gupta et al [15]. $60 \%$ of patients were operated within the first 24 hours, $7 \%$ were operated after the 72 nd hour.

Harissou A et al [8] reported in their series a surgical intervention time that varies from 1 hour to 48 hours after the indication for surgery with an average of 9 hours.

In our series, the time taken for treatment after admission of the patient to the emergency room was also long, longer than that of Harouna Y and Harissou A. This could be explained by the inaccessibility of certain additional emergency examinations due to the low power. purchase of patients who find it difficult to bear the costs (no health insurance).

Abdominal pain, a frequent reason for consultation, is the usual symptom faced by visceral surgeons on call $(10 \%$ of all emergency room visits) [5]. From various causes, often digestive, sometimes extradigestive, surgical or medical, its management in emergencies must therefore be pragmatic and rapid [5]. Chaibou MS et al. [11] in2010 reported in their series a frequency of $98.4 \%$ of abdominal pain and $77.3 \%$ of vomiting. Racotomavo F. A et al [16] in 2012 reported in their study that abdominal pain was the main symptom, present in all their patients, ie $100 \%$ of cases; followed by nausea and vomiting $(63,33 \%)$ and abdominal distension $(56.66 \%)$.

In our series, abdominal pain was the most common reason 
for consultation, this shows that emergency digestive surgery most often comes down to the diagnosis and management of acute abdominal pain. Its semiological characteristics and other associated signs allowed in all our cases, diagnostic orientation.

Four major clinical syndromes constitute the bulk of digestive surgical emergencies: peritoneal, occlusive, appendicular and traumatic abdominal syndromes [3]. Chaibou MS et al [11] in 2010 reported in their series that the reasons for intervention were represented by peritoneal syndromes in $38.43 \%$ of cases, occlusive syndromes in $24.54 \%$ of cases, appendicular syndrome in $15.9 \%$ of cases. Abdominal contusions and wounds represented $10.98 \%$ and $1.96 \%$ of cases, respectively.

In the series by Harissou A et al [8], the main indications for surgery were peritonitis ( 156 cases), ie $60 \%$ of cases; intestinal obstruction (85 cases), or $28 \%$ of cases; acute appendicitis (25 cases) or $8 \%$ of cases; abdominal trauma (29 cases) or $10 \%$ of cases. Harouna $\mathrm{Y}$ et al [3] found in their series a predominance of occlusive syndrome in $41 \%$ of cases, followed by peritoneal and appendicular syndromes in 28.2 and $20.8 \%$ of cases. In our series, as in that of Chaibou MS and Harissou A. et al. the reasons for intervention were dominated by peritoneal, occlusive, appendicular and abdominal traumatic syndromes. The leading cause of abdominal surgical emergency, mechanical occlusion is clearly predominant with a frequency varying from 95 to $100 \%$ [3]. In Africa, the leading cause of mechanical occlusion is strangulation, ie $93.5 \%$ of cases [3]. Strangulated hernia and pelvic colon volvulus are the most common etiologic diagnoses in Africa, while in Europe occlusions by flanges or tumor obstruction predominate [3]. Peritonitis takes second place with a frequency of $28.8 \%$ of abdominal surgical emergencies [9].

In the series by Harouna YD et al [16], in 143 patients or $89 \%$ of the sample, it was secondary peritonitis. Digestive perforation was the cause in $54 \%$ of cases and septic diffusion in $45 \%$ of cases. In descending order, the causes of secondary peritonitis were: Typhoid perforation of the small intestine $35 \%$ of cases; appendicitis complicated $33.5 \%$ of cases; peptic ulcer perforations $11 \%$ of cases; traumatic peritonitis $2.5 \%$ and biliary peritonitis $2 \%$ of cases.

In the series by Chaibou MS et al [11], peritonitis occupied the first place, ie $38.43 \%$ of cases, followed by mechanical occlusion in $24.54 \%$ of cases. Gastroduodenal and appendicular perforation were the most frequent etiologic diagnoses in the series by Rakotomavo et al [16]. Gastric perforation was the most common cause of secondary peritonitis, $69.24 \%$ of cases followed by duodenal $7.69 \%$ of cases.

In our series, as in that of Chaibou MS and Rakotomavo et al, gastroduodenal and appendicular perforation were the most frequent etiological diagnoses of acute generalized peritonitis. The etiologies of mechanical occlusions were dominated by strangulated hernias and postoperative flanges.

The management of digestive surgical emergencies is medico-surgical, combining adequate antibiotic therapy, rapid control of the source of infection which requires surgical intervention; hemodynamic and hydroelectrolyte balance is often necessary because of the delay in management which leads the patient to severe sepsis and septic shock [3]. In the series by Lebeau R. et al. [7], antibiotic prophylaxis and hemodynamic and electrolyte balance were achieved in most of their patients.

The prognosis of digestive surgical emergencies depends on the earliness of the treatment, the development of the condition, the quality of the initial surgical treatment and whether or not the defects have decompensation [7]. Load is essential for the success of emergency surgery [8]. Despite the progress in management, the morbidity and mortality rates in the different series are still significant and variable. Early and adequate management could improve outcomes. [16]. In France, a study at Saint Antoine Hospital reported a $20 \%$ mortality rate in digestive surgery in elderly subjects. For many African authors [10] parietal suppurations constitute the main postoperative complications of digestive surgical emergencies. This could be explained by the fact that digestive emergencies present themselves in a picture of severe infection and under nutrition. In the series by LeBeau $\mathrm{R}$ et al. [7], postoperative complications were dominated by parietal infection, ostomy complications, digestive fistula, scrotal hematoma, and evisceration. A mortality of $10.21 \%$ $(n=14)$ was reported linked to delayed treatment and medical defects. Harissou et al [8], reported an overall mortality of $12 \%$. Peritonitis was the leading cause of death $(64 \%)$ followed by OIA $(25 \%)$.

Harouna states that the delay in treatment clearly influences mortality, increasing from $14 \%$ before the 24th hour to $22 \%$ after the 48 th hour [3]. In the series by $\mathrm{N}$. rasamoelina et al [14]. the causes of death were dominated by hypovolemic shock $(n=10)$ and septic shock $(n=9)$. In our series, regardless of any etiology, the postoperative consequences were simple in more than half of the cases, the postoperative complications observed were dominated by parietal infections, especially encountered during peritonitis and contributed to the lengthening of the duration. After the patients' stay in hospital came digestive fistula and scrotal hematoma. The mortality in our study as reported in the literature was higher than that of LeBeau $\mathrm{R}$ et al. And Harissou A. Peritonitis was the leading cause of death from poly visceral failure related to septic shock in bowel obstruction and trauma to the abdomen. This high mortality in our study as reported by many African authors (Harouna et al, Rasamoelina) was influenced by the delay in the management of digestive surgical emergencies.

This delay was linked on the one hand to the patients who could not meet the medical prescriptions and on the other hand to the inadequacy of the hospital's care circuit. Even if the patient has the means, he can lose sufficient time in acquiring additional tests and certain products such as blood. The factors incriminated in our study were: insufficient pre, per and post-operative resuscitation, the pecuniary problem of the patients, the delay in consultation, late evacuation and especially the insufficiency of the technical platform.

The hospital stay in the different African series remains 
important linked to the delay in diagnosis and to the operative complications: it was 12 days in the series by $\mathrm{N}$. Rasamoelina et al. [14]; 7.7 days with extremes of 2 and 23 days in the LeBeau $\mathrm{R}$ series [7]. In our series, regardless of any etiology, the hospital stay was long comparable to that of N. Rasamoelina et al.

Acute generalized peritonitis was by far the cause of our patients' prolonged stay with bowel obstruction and trauma to the abdomen.

\section{Conclusion}

Digestive surgical emergencies occupy a prominent place in surgical pathology due to their high frequency. The aetiologies are many and varied, hence the need for close multidisciplinary collaboration. The management of these emergencies still remains a challenge, both curatively and preventively. In fact, morbidity and mortality would be significantly reduced by reducing the diagnostic delay which is often linked to the dysfunction of the care system in our hospitals and / or to the problems of access to care encountered by patients.

\section{Conflicts of Interest}

All the authors do not have any possible conflicts of interest.

\section{References}

[1] Etienne J. C. Diagnostic des douleurs abdominales aigues. Encyclopédieméd. Chir, urgence; Paris1998; 24-039B-10.

[2] Harouna Y., Ali L., Seibou A., AbdouI. Gamatie Y. Et coll. Deux ans de chirurgie digestive D'urgence a l'hôpital national de Niamey (NIGER): Étude analytique et pronostique, Médecine d Afrique Noire. 2001; 48 (2): 49-54.

[3] Dr Jean Marc Hoany. Urgences en chirurgie digestive, service de chirurgie digestive et générale CHI de Raincy MontFerrail. 0141708110, Cours IFSI de maison Blanche, Mai2005.

[4] Lebeau R., Diané B., Kassi ABF, Yénon KS, Kouassi JC. Urgences abdominales digestives Non traumatiques chez les sujets âgés au CHU de Cocody, cote d'ivoire: étiologie et résultats thérapeutiques. Med Trop. 2011; 71: 24-44.

[5] HarissouA., Amadou MM., Oumarou Hetal. Retard diagnostique et implication pronostique en Milieu Africain. Cas des urgences en chirurgie digestive à 1 'hôpital national de Zinder, Niger. E uropean Scientific, 2015; 11, (12): 1857-788.
[6] Cassina Petal. Dieeffezienz der chirurgishengrund diaggnostukbein adominal schmerz. Der Chirurg 1996; 67: 245-260.

[7] Solagberu B A, Duze A. T, Kuranga A O, Ofoegbu CK, O delowo E O. Surgical Emergencies in university hospital. Niger prostgrad Med J 2005; 10 (3): 140-143.

[8] Chaibou MS, Sani R, Daddy H, Kotannou M, Sanoussi S: Prise en charge per opératoire des urgences abdominales aigues à l'hôpital national de Niamey (HNN), Département D'Anesthésie-Réanimation-Urgences-Hôpital National de Niamey- Niger, RAMUR me 17, -(Spécial congrès); 2012, 4: 8

[9] Mushtaq A Mehbood AliS, Stphen L, Philomène DJ, Sifat W. Survey of chirurgical emergencies in the rural population in the Northen areas of Pakistan. Trop Med and Int Health 1999; 12: 846 .

[10] A Sima Zué, A Josseaume, D Ngaka Nsafu, L Galoisy-Guibal, JP Carpentier. Les urgences chirurgicales au centre hospitalier de Libreville; annales française d'anesthésie et de Réanimation, 2003; 22-(3): 189-95.

[11] Keita M, Camara B, Goita D, Dicko H, Diallo D, Diallo B: Caractéristiques Épidémiologiques des patients admis à l'unité d'accueil des urgences, Service Anesthésie - Réanimation et des Urgences CHU du Point G-Bamako-, RAMUR me 17, (spécial congrès 2012; 4: 3).

[12] Charles-André Cuenod., Philippe Wind., Nathalie sauve. Diagnostic des urgences abdominales aigues d'origine digestive chez l'adulte: Gastroentérologie, clinique et biologique, 1999; 23 (11): 1170.

[13] N Rasamoelina., T Rajaobelison., M. F Ralahy., A. M Riel. Facteurs de mortalité par les urgences digestives dans le service de réanimation du CHU de Fianarantsoa Madagascar. Revue d'Anesthésie-Réanimation et de Médecine d'Urgence; 20102 (2): 10-11.

[14] Gupta SK., Gupta R., Singh G., et al. Perforation peritonitis: a two years' experience. JK Science, 2010; 3: 141-4

[15] F. ARakotomavo., R. C. N Rakotoarison., H. Randrianambinina., T. Randriamiarana., M. J Randrianambinima. Péritonite aigue: aspects epidemioclinique et étiologique dans un service des urgences chirurgicales Malgache. A propos de 60 cas. Journal Africaine d' Hépato-Gastroentérologie 03/2012/; 6 (1). DOI 10.1007.

[16] Y. D. Harouna, I. Abdou, B. Saibou, L. Bazira. Les péritonites en milieu tropical. Particularités étiologiques et facteurs pronostiques actuels-A propos de 160 cas. Médecine d'Afrique Noire 2001; 48 (3): 104-106. 